\title{
Immunohistochemical Analysis of Cell Cycle- Related Molecules in Gastric Carcinoma: Prognostic Significance, Correlation with Clinicopathological Parameters, Proliferation and Apoptosis
}

\author{
Kyung-Hee Lee ${ }^{a}$ Hee Eun Lee ${ }^{f}$ Sung Jin Cho ${ }^{a}$ Yu Jin Cho ${ }^{a}$ Hye Seung Lee \\ Ji Hun Kim ${ }^{d}$ Seon Young Nam ${ }^{e}$ Mee Soo Chang ${ }^{b}$ Woo Ho Kim ${ }^{b}$ \\ Byung Lan Lee ${ }^{a, c}$ \\ ${ }^{a}$ Department of Anatomy, ${ }^{b}$ Department of Pathology and ${ }^{\mathrm{C}}$ Ischemic/Hypoxic Disease Institute, Seoul National \\ University College of Medicine, ${ }^{d}$ Department of Pathology, Asan Medical Center, University of Ulsan College of \\ Medicine, ${ }^{e}$ Division of Radiation Effect Research, Radiation Health Research Institute, Korea Hydro and Nuclear \\ Power Co., Seoul, and f Department of Pathology, Seoul National University Bundang Hospital, Seongnam, Korea
}

\section{Key Words}

Cell cycle regulator · Gastric cancer · Tissue array • Immunohistochemistry $\cdot$ Proliferation $\cdot$ Apoptosis

\begin{abstract}
Objective: We aimed to investigate the biological significance of cell cycle regulators in gastric carcinoma. Methods: Immunohistochemistry and TUNEL staining were performed on tissue array slides containing 293 gastric carcinoma specimens. The relationship between the protein expression of each of the cell cycle regulators and prognosis, clinicopathological features, proliferation, or apoptosis was evaluated. Results: The nuclear immunoreactivity for cyclin D1, cyclin E, p21, and p27 was observed in 22, 14, 31 and $27 \%$ of cases, respectively. The expression of cyclin D1, p21, or p27 positively correlated with early pTNM stages, tumor cell proliferation (represented by Ki-67 labeling) and good prognosis, whereas it inversely correlated with the lymph node metastasis $(p<0.05)$. On the other hand, p27 expression inversely
\end{abstract}

\section{KARGER}

Fax +41613061234 E-Mail karger@karger.ch www.karger.com
(C) 2008 S. Karger AG, Basel

$1015-2008 / 08 / 0756-0364 \$ 24.50 / 0$

Accessible online at:

www.karger.com/pat correlated with the apoptosis index represented by TUNEL staining ( $p<0.001)$. In addition, the expression of cyclin D1 positively correlated with that of p21 or p27 ( $p<0.05)$. Conclusions: Our results showed that the expression of cyclin D1, p21 and p27, alone or in combination, are early events in gastric tumorigenesis and may serve as a candidate molecular marker for the early gastric carcinoma.

Copyright $\odot 2008$ S. Karger AG, Basel

\section{Introduction}

Gastric cancer is one of the most common malignancies worldwide and the major cause of cancer-related death in Asian countries. Since gastric cancer diagnosed at an advanced stage has been associated with a high lethality, early detection is important for successful treat-

K.-H. Lee and H.E. Lee contributed equally to this work.
Dr. Byung Lan Lee

Department of Anatomy, Seoul National University College of Medicine

28 Yeongon-dong, Chongno-gu

Seoul 110-799 (Korea)

Tel. +82 2740 8206, Fax +82 2745 9528, E-Mail dslanat@snu.ac.kr 
ment. Thus, the detection of prognostic markers may enable us to anticipate the evolution of this disease, allowing a more effective management of the patient.

A fundamental cause of cancer is the alteration of the genetic material, which may modulate the expression of proteins that play key roles in cell cycle progression. In particular, abnormal expressions of cell cycle-regulatory proteins that control G1-S phase transition, a critical ratelimiting step in cell cycle progression, are frequently observed. The relevant proteins include three D-type cyclins (D1, D2, and D3) that bind to one of two cyclin-dependent protein kinase (CDK) subunits, CDK4 and CDK6, as well as the E-type cyclins, which govern the activity of a single catalytic subunit, CDK2 [1]. Furthermore, inactivation of CDK inhibitors, p21 ${ }^{\text {Waf1/Cip1 }}$ (p21) and $\mathrm{p} 27^{\mathrm{Kip} 1}$ (p27), which normally cause G1 arrest by binding to cyclin-CDK complexes, is often observed in diverse human tumors [2].

The overexpression of G1 cyclins as well as loss of G1 cyclin-related CDK inhibitors have been generally associated with tumor progression and/or poor prognosis in various types of tumors including pancreatic cancer [3], colorectal cancer [4], and esophageal cancer [5]. However, contradictory findings also have been reported. Cyclin D1 overexpression was associated with low-grade tumors of breast carcinomas [6]. The overexpression of cyclin $\mathrm{E}$ had no prognostic value in anal cancer [7], cervical cancer [8] and gastrointestinal stromal tumor [9]. The expression of $\mathrm{p} 27$ positively correlated with poor prognosis in esophageal squamous carcinoma [10]. Thus, the role of these proteins in the prognosis of human cancers needs to be investigated in each cancer type.

With respect to gastric cancer, the biological significance of G1 cyclins remains unclear. Previous studies reported that cyclin $\mathrm{D} 1$ has no prognostic value in gastric cancer $[11,12]$. The expression of cyclin $\mathrm{E}$ in gastric cancer correlated with either good prognosis [11] or poor prognosis [13], whereas an earlier study demonstrated that the overexpression of cyclin $\mathrm{E}$ has no prognostic value [14]. Regarding CDK inhibitors in gastric cancer, loss of p21 or p27 has been generally associated with good prognosis $[11,15,16]$. On the contrary, no correlation between prognosis and the expression of p21 $[17,18]$ or p27 [18-20] has also been noted. Thus, it is difficult, on the basis of the results reported so far, to comprehensively explain the role of cyclins D1 and E as well as p21 and p27 in the pathogenesis of gastric cancer.

In the present study, we evaluated the expression of cyclins D1 and E and the CDK inhibitors p21 and p27 in 293 surgically excised human gastric carcinoma tissues using immunohistochemistry performed on the tissue array slides. Then, we analyzed their relationship with the prognostic significance and clinicopathological parameters. The alterations identified have been further correlated with proliferation and apoptosis in gastric cancer.

\section{Materials and Methods}

\section{Patients}

The files of 293 surgically resected gastric cancer cases examined at the Department of Pathology, Seoul National University College of Medicine (Seoul, Korea) from January 1 to June 30, 1995 were analyzed [21]. Age, gender, tumor location, Lauren's classification, pTNM stage, lymphatic invasion, lymph node metastasis, and distant metastasis were evaluated by reviewing medical charts and pathological records. The mean age of the patients was 54.8 years, and $93.3 \%$ of the patients had undergone curative resection. The cases enrolled in this study included 211 advanced and 82 early-stage gastric carcinomas. According to the pTNM classification, 120 cases were in stage 1, 56 in stage II, 68 in stage III, and 49 in stage IV. No patient had received preoperative chemotherapy or radiotherapy. Glass slides were reviewed to determine the histological type according to the WHO and Lauren's classification. This series included 111 intestinal types, 150 diffuse types, and 32 cases of mixed types. Clinical outcomes were followed from the date of surgery to either the date of death or December 1,2000 , resulting in a mean follow-up period of 54 months ranging from 1 to 72 months. This protocol was reviewed and approved by the Institutional Review Board of Seoul National University (Approval No. C-0511-519-163).

\section{Tissue Array Methods}

Six array blocks containing a total of 293 tissue cores obtained from patients with a gastric cancer were prepared by Superbiochips (Seoul, Korea) as described previously [21]. Briefly, core tissue biopsies ( $2 \mathrm{~mm}$ in diameter) were taken from individual paraffin-embedded gastric tumors (donor blocks) and arranged in the new recipient paraffin blocks (tissue array block) using a trephine apparatus. The staining results of the different intratumoral areas of gastric carcinomas in these tissue array blocks showed an excellent agreement. A core was chosen from each case for analysis. We defined an adequate case as a tumor occupying more than $10 \%$ of the core area. Each block contained internal controls consisting of nonneoplastic gastric mucosa from body, antrum, and other areas showing intestinal metaplasia. Sections of $4-\mu \mathrm{m}$ thickness were cut from each tissue array block, deparaffinized, and dehydrated.

\section{Immunohistochemistry}

Immunohistochemical staining was performed as described previously [21] using a streptavidin peroxidase procedure (avidinbiotin complex method) after autoclave-based antigen retrieval. The primary antibodies used were anti-cyclin D1 (1:500, Santa Cruz Biotechnology, Santa Cruz, Calif., USA), anti-cyclin E (1:100, Santa Cruz Biotechnology), anti-p21 (1:100, Santa Cruz Biotechnology), anti-p27 (1:100, Oncogene, Cambridge, Mass., 
Fig. 1. Immunohistochemical staining for cell cycle regulators. $\times 200$. a Ki-67-positive. b TUNEL-positive. c Cyclin D1-positive. d p21-positive. e p27-positive. f Negative control without primary antibody.

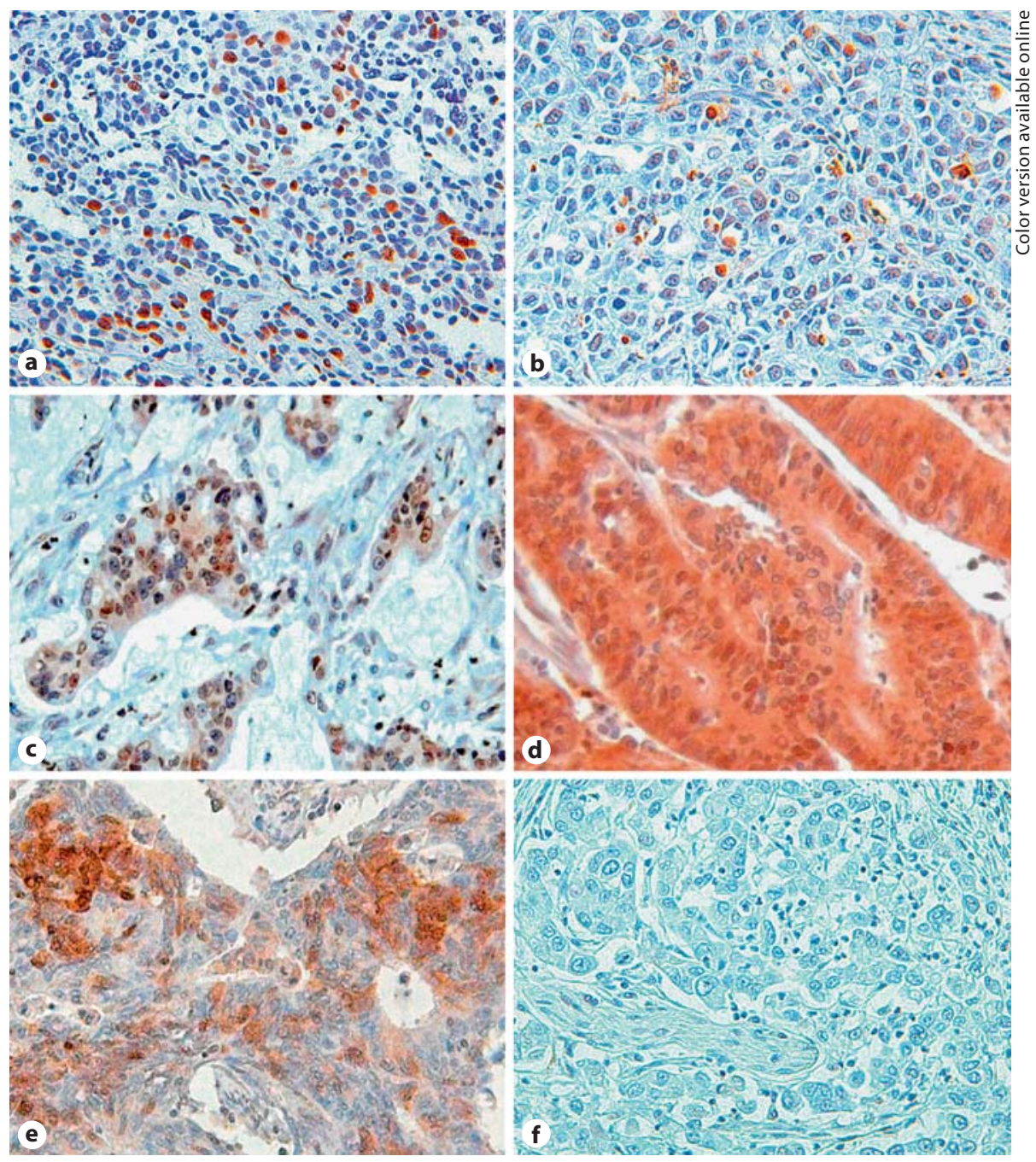

USA) and anti-Ki-67 (1:50, Santa Cruz Biotechnology), anti-p27 (1:100, Oncogene, Cambridge, Mass., USA) and anti-Ki-67 (1:50, Santa Cruz Biotechnology). Cancer cells showing nuclear staining regardless of cytoplasmic staining were regarded as expressing the proteins. For statistical analysis of immunostaining for proteins other than $\mathrm{Ki}-67$, cases showing nuclear staining in more than $10 \%$ of the tumor cells were considered positive. For Ki-67 staining, we evaluated 300 cells and counted the cells with nuclear staining for each specimen. The proliferation index was defined as follows: proliferation index $(\%)=100 \times$ Ki-67-positive cells/total cells.

\section{TUNEL Staining}

Apoptotic cells were identified by the terminal deoxynucleotidyl transferase-mediated deoxyuridine triphosphate biotin nick end labeling (TUNEL) method using an apoptosis detection kit (Chemicon International, Temecula, Calif., USA). Labeling procedures were performed according to the manufacturer's instruction, which was followed by staining with diaminobenzidine for 2 min and counterstaining with hematoxylin. In total, 300 cells were counted for each specimen. The apoptotic index was defined as follows: apoptotic index $(\%)=100 \times$ apoptotic cells/total cells.

Statistical Analysis

All statistical analyses were conducted using SPSS version 11.0 software (SPSS, Chicago, Ill., USA). Survival curves were estimated using the Kaplan-Meier product-limit method, and the significance of differences between the survival curves was determined using the log-rank test. To determine whether the expression of cyclin D1, p21, or p27 is an independent prognostic variable, multivariate survival analysis was performed using the Cox proportional hazard model. The significance of correlation between the expression of cell-cycle regulator and the clinicopathological characteristics was determined by either the $\chi^{2}$ test or the Fisher exact test (two-sided). The relationship between the expression of cell cycle regulator and the apoptosis or cell proliferation index was analyzed using the two-tailed Student $t$ test. The results were considered statistically significant when $\mathrm{p}<0.05$. 
Fig. 2. Kaplan-Meier curves for patient survival. The expression of cyclin D1 (a), p21 (c), or p27 (d) was positively correlated with good prognosis, whereas that of cyclin E (b) was not associated with patient survival.
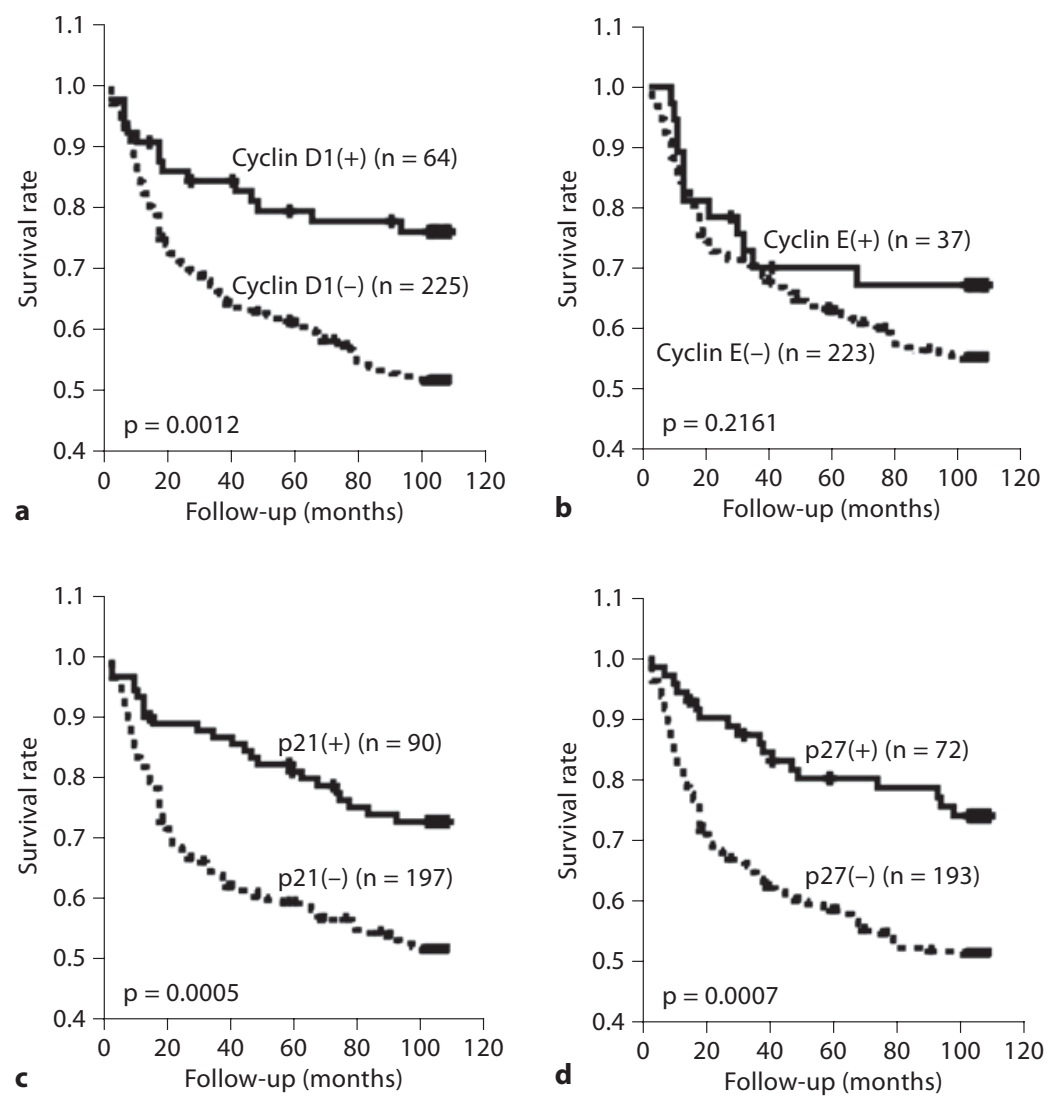

\section{Results}

\section{Expression of Cell Cycle Regulators}

Representative results of the immunohistochemical staining are shown in figure 1. Immunohistochemistry for Ki-67 showed nuclear immunoreactivity in proliferative cells (fig. 1a). TUNEL staining demonstrated fragmented nuclei of apoptotic cells (fig. 1b). Regarding cell cycle regulators cyclin D1 (fig. 1c), p21 (fig. 1d) and p27 (fig. 1e), immunoreactivity was present in both nucleus and cytoplasm. Tumor cells showing nuclear staining, regardless of the presence of the cytoplasmic staining, were considered as positively immunostained. Of the 293 cases analyzed, the nuclear protein expression of cyclin D1, cyclin E, p21, and p27 was observed in 22, 14,31 and $27 \%$ of gastric cancer specimens, respectively (table 1).

Cell Cycle Regulators in Gastric Cancer

\section{Expression of Cell Cycle Regulators in Relation to Prognosis}

In order to analyze the correlation between survival rate of the gastric cancer patients and the expression of each of cyclins D1 and E, and p21 and p27 (fig. 2), we used a log-rank test with Kaplan-Meier estimates. Patients with nuclear expression of cyclin D1 (fig. 2a), p21 (fig. 2c) or p27 (fig. 2d) showed a higher survival rate than those with only cytoplasmic expression or negative staining $(\mathrm{p}=0.0012, \mathrm{p}<0.001$ and $\mathrm{p}<0.001$, respectively). In the combined analysis, patients with a cyclin D1-positive and p21-positive tumor or those with a cyclin D1-positive and p27-positive tumor showed a higher survival rate than the remainder of the population $(\mathrm{p}<0.001$ and $\mathrm{p}=0.002$, respectively; fig. 3a, b). However, multivariate analysis using Cox's proportional hazards regression model indicated that cyclin D1, p21, and p27 could not be proven as an independent prognostic parameter $(\mathrm{p}=0.196,0.087$ and 0.617 , respectively). In addition, there was no signifi- 
Fig. 3. Kaplan-Meier curves for patient survival. a Patients with cyclin D1-positive and p21-positive combination showed the best outcome $(\mathrm{p}<0.001)$. b Patients with cyclin D1-positive and p27-positive combination showed better outcome than those with the other combinations ( $p=0.003$ ).
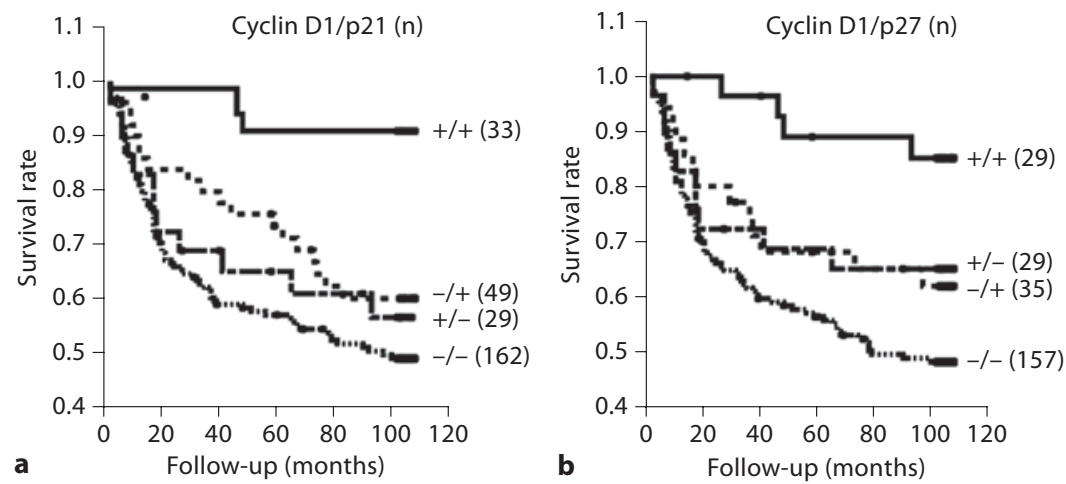

Table 1. Correlation between the nuclear expression of cyclin D1, p21 or p27 and clinicopathological parameters in gastric carcinomas

\begin{tabular}{|c|c|c|c|c|c|c|c|c|c|}
\hline & \multicolumn{2}{|c|}{ Cyclin D1 } & \multirow[t]{2}{*}{$\mathrm{p}$ value } & \multicolumn{2}{|l|}{$\mathrm{p} 21$} & \multirow[t]{2}{*}{$\mathrm{p}$ value } & \multicolumn{2}{|l|}{$\mathrm{p} 27$} & \multirow[t]{2}{*}{$\mathrm{p}$ value } \\
\hline & positive & negative & & positive & negative & & positive & negative & \\
\hline Total & $64(22)$ & $229(78)$ & & $90(31)$ & $201(69)$ & & $72(27)$ & $197(73)$ & \\
\hline \multicolumn{10}{|l|}{ Age, years } \\
\hline $0-39$ & $17(35)$ & $31(65)$ & \multirow[t]{3}{*}{0.194} & $16(33)$ & $32(67)$ & \multirow[t]{3}{*}{0.752} & $20(43)$ & $27(57)$ & \multirow[t]{3}{*}{0.074} \\
\hline $40-65$ & $34(18)$ & $154(82)$ & & $57(30)$ & $129(70)$ & & $38(23)$ & $129(77)$ & \\
\hline 66-99 & $13(23)$ & $44(77)$ & & $17(30)$ & $40(70)$ & & $14(25)$ & $41(75)$ & \\
\hline \multicolumn{10}{|l|}{ Gender } \\
\hline Male & 38 (19) & $165(81)$ & \multirow[t]{2}{*}{0.052} & $67(33)$ & 135 (67) & \multirow[t]{2}{*}{0.213} & $48(26)$ & $137(74)$ & \multirow[t]{2}{*}{0.652} \\
\hline Female & $26(29)$ & $64(71)$ & & $23(26)$ & $66(74)$ & & $24(29)$ & $60(71)$ & \\
\hline \multicolumn{10}{|l|}{ Location } \\
\hline Antrum & 30 (19) & $128(81)$ & \multirow[t]{2}{*}{0.201} & $53(35)$ & $100(65)$ & \multirow[t]{2}{*}{0.149} & $35(24)$ & $108(76)$ & \multirow[t]{2}{*}{0.366} \\
\hline Body, cardia & $34(25)$ & $101(75)$ & & $37(27)$ & $101(73)$ & & $37(29)$ & $89(71)$ & \\
\hline \multicolumn{10}{|c|}{ Lauren's classification } \\
\hline Intestinal & $16(14)$ & $95(86)$ & \multirow[t]{3}{*}{0.08} & $42(37)$ & $72(63)$ & \multirow[t]{3}{*}{0.326} & $23(23)$ & $75(77)$ & \multirow[t]{3}{*}{0.745} \\
\hline Diffuse & $41(27)$ & $109(73)$ & & $37(25)$ & $110(75)$ & & $43(30)$ & $100(70)$ & \\
\hline Mixed & $7(22)$ & $25(78)$ & & $11(37)$ & $19(63)$ & & $6(21)$ & $22(79)$ & \\
\hline \multicolumn{10}{|l|}{ pTNM stage } \\
\hline I & $39(32)$ & $81(68)$ & \multirow[t]{4}{*}{$<0.001^{\mathrm{a}}$} & $56(46)$ & $65(53)$ & \multirow[t]{4}{*}{$<0.001^{\mathrm{a}}$} & $49(44)$ & $63(56)$ & \multirow[t]{4}{*}{$<0.001^{\mathrm{a}}$} \\
\hline II & $11(20)$ & $45(80)$ & & $15(26)$ & $42(74)$ & & $8(16)$ & $43(84)$ & \\
\hline III & $10(15)$ & $58(85)$ & & $12(18)$ & $54(82)$ & & $11(17)$ & $52(83)$ & \\
\hline IV & $4(8)$ & $45(92)$ & & $7(15)$ & $40(85)$ & & $4(9)$ & $39(91)$ & \\
\hline \multicolumn{10}{|c|}{ Lymphatic invasion } \\
\hline Negative & $51(25)$ & $154(75)$ & \multirow[t]{2}{*}{0.055} & $78(38)$ & $127(62)$ & \multirow[t]{2}{*}{$<0.001^{\mathrm{a}}$} & $61(32)$ & $128(68)$ & $<0.001^{\mathrm{a}}$ \\
\hline Positive & $13(15)$ & $75(85)$ & & $12(14)$ & $74(86)$ & & $11(14)$ & $69(86)$ & \\
\hline Lymph node me & stasis & & & & & & & & \\
\hline Absent & $33(32)$ & $70(68)$ & $0.002^{\mathrm{a}}$ & $47(45)$ & $57(55)$ & $0.043^{\mathrm{a}}$ & $43(45)$ & $52(55)$ & $<0.001^{\mathrm{a}}$ \\
\hline Present & $31(16)$ & $159(84)$ & & $43(23)$ & $144(77)$ & & $29(17)$ & $145(83)$ & \\
\hline Distant metastas & & & & & & & & & \\
\hline Absent & $63(23)$ & $214(77)$ & 0.209 & $89(32)$ & $187(68)$ & & $69(27)$ & $186(73)$ & 0.766 \\
\hline Present & $1(6)$ & $15(94)$ & & $1(7)$ & $14(93)$ & & $3(21)$ & $11(79)$ & \\
\hline
\end{tabular}

Numbers in parentheses represent percentage. ${ }^{a}$ Considered to be statistically significant. 
Table 2. Correlation between the nuclear expression of cyclin D1, p21 or p27 and the proliferation index and the apoptotic index in human gastric cancer

\begin{tabular}{ccccc}
\hline & Ki-67, $\%$ & p value & TUNEL, \% & p value \\
\hline Cyclin D1 & & & & \\
Positive & $32.98 \pm 24.46$ & $0.002^{\mathrm{a}}$ & $3.07 \pm 2.52$ & 0.598 \\
Negative & $20.41 \pm 19.27$ & & $3.3 \pm 2.5$ & \\
p21 $1^{\text {waf1/Cip1 }}$ & & & & \\
$\quad$ Positive & $27.72 \pm 22.02$ & $0.018^{\mathrm{a}}$ & $2.87 \pm 2.42$ & 0.154 \\
$\quad$ Negative & $20.74 \pm 19.67$ & & $3.37 \pm 2.48$ & \\
p27 Kip1 & & & & \\
$\quad$ Positive & $27.91 \pm 22.11$ & $0.036^{\mathrm{a}}$ & $1.97 \pm 1.90$ & $<0.001^{\mathrm{a}}$ \\
Negative & $20.78 \pm 19.55$ & & $3.65 \pm 2.56$ & \\
\hline
\end{tabular}

Values represent mean \pm SD. ${ }^{\text {a }}$ Considered to be statistically significant.

cant correlation between the nuclear expression of cyclin $\mathrm{E}$ and patient survival rate $(\mathrm{p}=0.216)$ (fig. $2 \mathrm{~b}$ ).

Next, we examined the relation between the expression of cell cycle regulators and patients' prognosis in each of the pTNM stages I-III, and found that the expression of cyclin D1, p21, or p27 was not correlated with a survival rate in the same pTNM stage (data not shown).

Association between the Expression of Cyclin D1, p21 and 27 and Clinicopathological Factors

Data representing the correlation between the expression of cyclin D1, p21 and p27 and the clinicopathological features of the gastric cancer specimens are summarized in table 1 . Nuclear expression of cyclin D1 was more likely to be found in the early pTNM stages $(\mathrm{p}<0.001)$. Seventy-eight percent of nuclear cyclin D1-positive tumors were in pTNM stages I and II, while $22 \%$ were in stages III and IV. Moreover, we found an inverse correlation between the nuclear staining of cyclin D1 and lymph node metastasis $(p=0.002)$. Cyclin D1 expression tended to be associated with lymphatic invasion and gender $(\mathrm{p}=0.052$ and $\mathrm{p}=0.055$, respectively). No association was found between cyclin D1 expression and age, tumor location, Lauren's classification, or distant metastasis.

Gastric carcinomas expressing nuclear p21 were more prominent in early pTNM stages $(\mathrm{p}<0.001)$. Seventyeight percent of nuclear p21-positive tumors were in pTNM stages I and II, while $22 \%$ were in stages III and IV. Moreover, we found an inverse correlation between the nuclear staining of $\mathrm{p} 21$ and lymph node metastasis $(\mathrm{p}<0.001)$, lymphatic invasion $(\mathrm{p}<0.001)$ or distant me- tastasis $(\mathrm{p}=0.043)$. No correlation was found between nuclear expression of p21 and age, gender, location, or Lauren's classification.

The expression of $\mathrm{p} 27$ was significantly higher in early pTNM stages $(p<0.001)$. Seventy-nine percent of nuclear p27-positive tumors were pTNM stage I and II, while $21 \%$ were in stages III and IV. Moreover, we found an inverse correlation between the nuclear staining of p27 and lymphatic invasion $(\mathrm{p}<0.001)$ or lymph node metastasis $(\mathrm{p}<0.001)$. No correlation was found between nuclear expression of p27 and age, gender, location, Lauren's classification, or distant metastasis.

Association between the Expression of Cyclin D1, p21 or p27 and Proliferation or Apoptosis

The results of the immunohistochemistry for Ki-67 and TUNEL staining are shown in table 2 . The percentages of Ki-67-positive cells and apoptotic cells were variable. The expression of cyclin D1, p21 and p27 significantly correlated with the proliferation index (evaluated by Ki-67 labeling). The expression of p27 inversely correlated with the apoptosis index (evaluated by TUNEL staining) whereas that of cyclin D1 or p21 did not show any association.

\section{Correlations between the Expression of Ki-67}

and That of p21 or p27 in Cyclin D1-Positive and

Cyclin D1-Negative Group

To remove the possible confounding effect of cyclin D1 on the relationship between Ki-67 and p21 or p27, we divided the staining data into two groups according to the expression of cyclin D1. Although expression of $\mathrm{p} 21$ or 277 correlated significantly with that of $\mathrm{Ki}-67$ in overall patients, there was no significant correlation after we removed the effect of cyclin D1 expression (table 3).

Correlations between Apoptosis and Histological Type

We analyzed the apoptotic index in relation to histological type in our specimens. We found that the apoptotic index in the intestinal gastric carcinomas was not significantly higher than in the diffuse carcinomas (3.11 \pm 2.1 and $3.16 \pm 2.7 \%$, respectively; $\mathrm{p}=0.865$ ) (data not shown).

\section{Discussion}

Previous reports on the prognostic implication of cell cycle regulators in gastric carcinomas have been inconsistent [11-20]. Thus, the present study obtained tissue 
Table 3. Correlation between the nuclear expression of Ki-67 and each protein in cyclin D1-positive and cyclin D1-negative group

\begin{tabular}{lll}
\hline & Ki-67, \% & p value \\
\hline $\begin{array}{l}\text { Cyclin D1-positive } \\
\text { p21 Waf1/Cip1 }\end{array}$ & \\
Positive & & \\
Negative & $35.71 \pm 25.14$ & 0.286 \\
p27 Kip1 & $27.85 \pm 22.64$ & \\
$\quad$ Positive & $33.47 \pm 22.46$ & 0.717 \\
$\quad$ Negative & $30.80 \pm 26.07$ & \\
\hline Cyclin D1-negative & & \\
p21 Waf1/Cip1 & & \\
$\quad$ Positive & & \\
$\quad$ Negative & $23.60 \pm 19.20$ & 0.259 \\
p27 Kip1 & $19.82 \pm 19.24$ & \\
$\quad$ Positive & & \\
$\quad$ Negative & $24.94 \pm 22.49$ & 0.146 \\
\hline
\end{tabular}

Values represent mean $\pm \mathrm{SD}$.

specimens from a large consecutive series of gastric cancer patients sourced from a single referral center, all of whom had been treated using similar surgical and adjuvant chemotherapy regimes. Then, we determined the expression levels of several key proteins regulating G1-S phase progression using the tissue array technique which enables us to perform the large-scale molecular studies processed in identical conditions and obtain consistent immunohistochemical results. To the best of our knowledge, the present study is the first study that shows a positive correlation between the expression of cyclin D1 and that of the CDK inhibitors p21 and p27 as well as good prognosis in gastric cancer.

Earlier studies on gastric cancer reported that cyclin D1 expression does not correlate with survival outcome of gastric cancer patients $[11,12,19]$. In the present study, the nuclear expression of cyclin D1 positively correlated with good prognosis in the univariate analysis and was more prominent in early-stage pTNM tumors than in late-stage tumors. Moreover, cyclin D1 expression inversely correlated with nodal metastasis, which is one of the most important factors in determining the prognosis of gastric carcinomas [22]. Similar results were previously shown in breast cancer [6], non-small-cell lung cancer [23], bladder cancer [24] and colorectal cancer [25]. On the other hand, cyclin D1 expression positively correlated with the Ki-67 labeling index $(\mathrm{p}=0.002)$, but not with the apoptosis index $(\mathrm{p}=0.598)$. These findings indicate that cyclin D1 expression is an early event of gastric tumorigenesis and involved in abnormal cell proliferation. Thus, cyclin D1 might be a candidate molecular biomarker for the early gastric carcinoma.

Cyclin D1 is generally regarded to be the promoter of tumor growth. Indeed, our data in the present study showed a positive correlation between the expression of cyclin $\mathrm{D} 1$ and the proliferation index (evaluated by Ki-67 labeling). When we analyzed the association between the pTMN stage and proliferation index, the proliferation index was $25.46 \pm 21.32 \%$ in early stages (I and II) and $13.34 \pm 15.37 \%$ in late stages (III and IV) $(p<0.001$; data not shown). These findings indicate that the proliferation rate in gastric carcinoma is higher in early stages than in late stages. Thus, this might be the reason why cyclin D1 expression is higher in early-stage gastric carcinomas. This speculation is substantiated by our previous studies which showed that the activation of AKT (protein kinase B) was more frequent in early-stage gastric carcinomas [26], although AKT promotes gastric cancer growth [27].

Previously, it was reported that loss of expression of p21 or p27 correlates with poor prognosis of gastric cancer $[11,15,16]$, whereas Al-Moundhri et al. [18] suggested that the expression of p21 or p27 is not associated with survival rate of Arab patients. Thus, a consensus has not been reached concerning the prognostic value of p21 or p27 expression in gastric cancer. Our survival analysis in the present study demonstrated that the expression of $\mathrm{p} 21$ or p27 correlates with good survival of gastric cancer patients. Moreover, the expression of p21 or p27, like that of cyclin D1, seems to be an early event of gastric tumorigenesis because it correlates with early pTNM stages $(\mathrm{p}<$ $0.001)$, absence of lymphatic invasion $(\mathrm{p}<0.001)$ and lymph node metastasis $(\mathrm{p}<0.001)$.

In the present study, the expression of cyclin D1 showed a strong positive correlation with that of $\mathrm{p} 21$ $(\mathrm{p}<0.001)$ or $\mathrm{p} 27(\mathrm{p}<0.001)$. Although most of the previous studies generally reported that cyclin D1 and p21 or p27 have an opposing role in cell cycle progression [28], our findings are consistent with those shown in renal cancer [2], in colorectal cancer [25] and in breast cancer [29]. Previously, several suggestions have been made to explain this relationship. First, it was hypothesized that the true determining factor of cell proliferation is the balance between the two opposing regulators of cell proliferation and that rapidly proliferating cancer cells might overcome the inhibition of p21 or p27 by overexpression of cyclin D1 [29]. However, this explanation does not seem to be appropriate for the present study because ex- 
pression of p21 or p27 did not show inverse correlation with $\mathrm{Ki}-67$ labeling index after the removal of the effect of cyclin D1. Second, induction of p21 or p27 by the expression of cyclin D1 or vice versa has been suggested [29, 30]. Third, cyclin D1 inhibits the proteasome-mediated p21 degradation [31]. Finally, a possible coregulatory mechanism for cyclin D1, p21 and p27, for example, through dietary factors that can upregulate all of these molecules was suggested [25].

CDK inhibitors p21 and p27 are well-established cell cycle-negative regulators. In normal cells, an inverse correlation between p27 expression and cell proliferation was generally seen. In comparison, in case of human cancers such as breast cancer [29], bladder cancer [32], and laryngeal cancer [33], high-level expression of p21 or p27 was also seen in a variety of highly proliferative cancer cells. With respect to gastric cancer, a positive correlation between Ki-67 labeling and p27 has been reported [18]. In the present study, we confirmed that the expression of p21 or p27 positively correlates with the Ki-67 labeling index ( $\mathrm{p}=0.018$ and $\mathrm{p}=0.036$, respectively). However, after removing the possible confounding effect of cyclin D1, no significant correlation was detected between the expression of p21 or p27 and Ki-67 labeling index. So far, no study has noted this role of cyclin D1 in the regulation of p21 or p27 effect on the cell proliferation in gastric cancer cells. We hypothesize that a positive relationship between p21 or p27 and Ki-67 stems from a positive correlation between cyclin D1 and p21 or p27.

Our data showed that the expression of $\mathrm{p} 27$, but not that of p21 or cyclin D1, inversely correlates with apoptosis $(\mathrm{p}<0.001, \mathrm{p}=0.154$ and $\mathrm{p}=0.598$, respectively). Although p27 has been reported to promote apoptosis in gastric cancer [34,35], the antiapoptotic function of p27 has been demonstrated in leukemic cells and lung cancer cells in certain situations such as a lack of nutrients and hypoxia $[35,36]$, which is compatible with our result.

The assessment of biological prognostic factors is of clinical importance, especially for a disease with poor outcome, such as gastric cancer. The widely used pTNM staging has a high prognostic power, but of course, it cannot predict perfectly the outcome for a particular individual. Since interpatient diversity in tumor biology causes tumors with similar clinical or pathological characteristics to show a different clinical outcome, the combined analysis of several cell cycle regulator expressions may help predict patient outcome more accurately. In the present study, combined analysis showed that patients with cyclin D1-positive and p21/p27-positive gastric tumors show a better survival rate than the remainder of the population. This suggests that multiple targeting of cell cycle regulatory proteins will be a more effective strategy for the gastric cancer patients.

The present study showed that cyclin D1, but not cyclin E, correlated with prognosis of gastric cancer. These results are inconsistent with the findings of earlier studies that cyclin E, but not cyclin D1, has a prognostic significance in gastric carcinoma [11-13]. We speculate that these discrepancies between the previous results and ours, at least in part, may come from differences in the interpatient variability in tumor biology or experimental methods including the tissue array technique. Although tissue array analysis provides a more stable staining environment, it cannot evaluate the heterogeneity of the tumor. Thus, the expression profiles of these genes can be different in the invasion front lesion or the superficial lesion or in the middle of the tumor.

In conclusion, the present study showed that the expression of cyclin D1, p21 or p27 is more frequent in the early-stage gastric carcinomas and is significantly associated with negative nodal status and proliferation. In addition, the expression of cyclin D1, p21 or p27 was related to a good prognosis in gastric cancer patients although it failed to be an independent prognostic factor.

\section{Acknowledgments}

This work was supported by the Korea Research Foundation Grant funded by the Korean Government (MOEHRD, Basic Research Promotion Fund; KRF-2006-531-E00008). S.J. Cho and Y.J. Cho were supported by the second-stage Brain Korea 21 Project in 2006. We thank Superbiochips for their technical assistance.

References

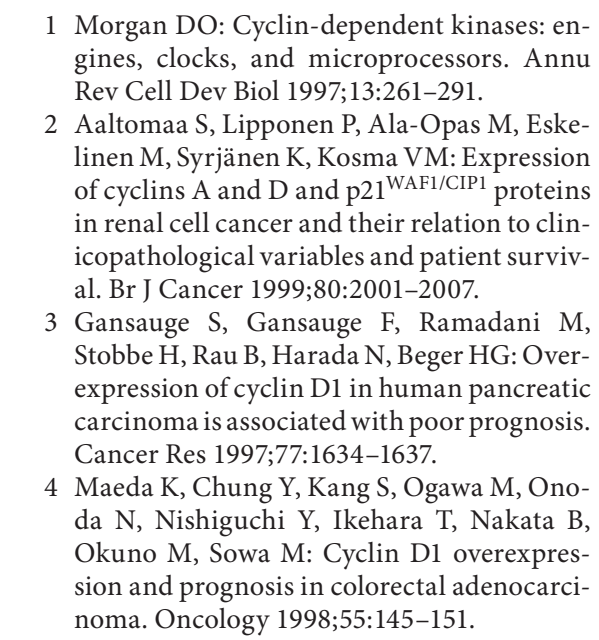

Pathobiology 2008;75:364-372 
5 Ishikawa T, Furihata M, Ohtsuki Y, Murakami H, Inoue A, Ogoshi S: Cyclin D1 overexpression related to retinoblastoma protein expression as a prognostic marker in human esophageal squamous cell carcinoma. $\mathrm{Br} \mathrm{J}$ Cancer 1998;77:92-97.

6 Gillett CE, Lee AH, Millis RR, Barnes DM: Cyclin D1 and associated proteins in mammary ductal carcinoma in situ and atypical ductal hyperplasia. J Pathol 1998;184:396400 .

7 Allal AS, Gervaz P, Bründler MA: Cyclin D1, cyclin E, and p21 have no apparent prognostic value in anal carcinomas treated by radiotherapy with or without chemotherapy. Br J Cancer 2004;91:1239-1244.

$>8$ Van de Putte G, Kristensen GB, Lie AK, Baekelandt M, Holm R: Cyclins and proliferation markers in early squamous cervical carcinoma. Gynecol Oncol 2004;92:40-46.

$\checkmark 9$ Nakamura N, Yamamoto H, Yao T, Oda Y, Nishiyama K, Imamura M, Yamada T, Nawata $\mathrm{H}$, Tsuneyoshi M: Prognostic significance of expressions of cell-cycle regulatory proteins in gastrointestinal stromal tumor and the relevance of the risk grade. Hum Pathol 2005;36:828-837.

-10 Ohashi Y, Sasano H, Yamaki H, Shizawa S, Shineha R, Akaishi T, Satomi S, Nagura H: Cell cycle inhibitory protein p27 in esophageal squamous cell carcinoma. Anticancer Res 1999;19:1843-1848.

-11 Takano Y, Kato Y, van Diest PJ, Masuda M, Mitomi H, Okayasu I: Cyclin D2 overexpression and lack of p27 correlate positively and cyclin E inversely with a poor prognosis in gastric cancer cases. Am J Pathol 2000;156: 585-594.

-12 Tenderenda M: A study on the prognostic value of cyclins D1 and E expression levels in resectable gastric cancer and on some correlations between cyclin expression, histoclinical parameters and selected protein products of cell-cycle regulatory genes. J Exp Clin Cancer Res 2005;24:405-414

-13 Jang SJ, Park YW, Park MH, Lee JD, Lee YY, Jung TJ, Kim IS, Choi IY, Ki M, Choi BY, Ahn MJ: Expression of cell-cycle regulators, cyclin $\mathrm{E}$ and $\mathrm{p} 21^{\mathrm{WAF} 1 / \mathrm{CIP} 1}$, potential prognostic markers for gastric cancer. Eur J Surg Oncol 1999;25:157-163.

14 Chetty R, Sitti CW: Cyclin E immunoexpression in gastric cancer does not correlate with clinicopathological parameters. Histopathology 2003;42:66-69.

-15 Gamboa-Dominguez A, Seidl S, Reyes-Gutierrez E, Hermannstädter C, QuintanillaMartinez L, Busch R, Höfler H, Fend F, Luber B:Prognostic significance of $21^{\mathrm{WAF} 1 / \mathrm{CIP} 1}$, p27 ${ }^{\text {Kip1 }}$, p53 and E-cadherin expression in gastric cancer. J Clin Pathol 2007;60:756761.
16 Mattioli E, Vogiatzi P, Sun A, Abbadessa G, Angeloni G, D'Ugo D, Trani D, Gaughan JP, Vecchio FM, Cevenini G, Persiani R, Giordano A, Claudio PP: Immunohistochemical analysis of pRb2/p130, VEGF, EZH2, p53, p16 ${ }^{\text {INK4A }}$, p27 ${ }^{\text {Kip1 }}$, p21 WAF1/CIP1, Ki-67 expression patterns in gastric cancer. J Cell Physiol 2007;210:183-191.

17 Kaye PV, Radebold K, Isaacs S, Dent DM: Expression of $\mathrm{p} 53$ and $\mathrm{p} 21^{\mathrm{WAF} 1 / \mathrm{CIP} 1}$ in gastric carcinoma: lack of inter-relationship or correlation with prognosis. Eur J Surg Oncol 2000;26:39-43.

18 Al-Moundhri MS, Nirmala V, Al-Hadabi I, Al-Mawaly K, Burney I, Al-Nabhani M Thomas V, Ganguly SS, Grant C: The prognostic significance of $\mathrm{p} 53, \mathrm{p} 27^{\mathrm{Kip} 1}$ p21 WAF1/CIP1, HER-2/neu, and Ki67 proteins expression in gastric cancer: a clinicopathological and immunohistochemical study of 121 Arab patients. J Surg Oncol 2005;91:243252.

19 Feakins RM, Mulcahy HE, Quaglia A Jawhari A, Zhang Z, Patchett SE: p27 Kip1 loss does not predict survival in patients with advanced gastric carcinoma. Cancer 2000;89: 1684-1691.

20 Wiksten JP, Lundin J, Nordling S, Kokkola A, von Boguslawski K, Haglund C: The prognostic value of p27 in gastric cancer. Oncology 2002;63:180-184.

21 Lee HS, Lee HK, Kim HS, Yang HK, Kim YI Kim WH: MUC1, MUC2, MUC5AC, and MUC6 expressions in gastric carcinomas: their roles as prognostic indicators. Cancer 2001;92:1427-1434.

22 Adachi Y, Kamakura T, Mori M, Baba H, Maehara Y, Sugimachi K: Prognostic significance of the number of positive lymph nodes in gastric carcinoma. Br J Surg 1994;81:414416.

23 Mishina T, Dosaka-Akita H, Kinoshita I, Hommura F, Morikawa T, Katoh H, Kawakami Y: Cyclin D1 expression in non-small-cell lung cancers: its association with altered p53 expression, cell proliferation and clinical outcome. Br J Cancer 1999;80:1289-1295.

-24 Tut VM, Braithwaite KL, Angus B, Neal DE, Lunec J, Mellon JK: Cyclin D1 expression in transitional cell carcinoma of the bladder: correlation with p53, waf1, pRb and Ki67. Br J Cancer 2001;84:270-275.

25 McKay JA, Douglas JJ, Ross VG, Curran S, Loane JF, Ahmed FY, Cassidy J, McLeod HL, Murray GI: Analysis of key cell cycle checkpoint proteins in colorectal tumors. J Pathol 2002;196:386-393.

26 Nam SY, Lee HS, Jung GA, Choi J, Cho SJ Kim MK, Kim WH, Lee BL: Akt/PKB activation in gastric carcinomas correlates with clinicopathologic variables and prognosis. APMIS 2003;111:1105-1113.
27 Lee BL, Kim WH, Jung J, Cho SJ, Park JW, Kim J, Chung HY, Chang MS, Nam SY: A hypoxia-independent up-regulation of hypoxia-inducible factor- 1 by AKT contributes to angiogenesis in human gastric cancer. Carcinogenesis 2008;29:44-51.

28 Banerji L, Glassford J, Lea NC, Thomas NS, Klaus GG, Lam EW: BCR signals target p2 $7^{\mathrm{Kip} 1}$ and cyclin D2 via the PI3-K signalling pathway to mediate cell cycle arrest and apoptosis of WEHI 231 B cells. Oncogene 2001;20:7352-7367.

-29 Fredersdorf S, Burns J, Milne AM, Packham G, Fallis L, Gillett CE, Royds JA, Peston D, Hall PA, Hanby AM, Barnes DM, Shousha S, O’Hare MJ, Lu X: High level expression of p2 $7^{\mathrm{Kip} 1}$ and cyclin D1 in some human breast cancer cells: inverse correlation between the expression of $\mathrm{p} 27^{\mathrm{Kip} 1}$ and degree of malignancy in human breast and colorectal cancers. Proc Natl Acad Sci USA 1997;94:63806385.

30 Han EK, Begemann M, Sgambato A, Soh JW, Doki Y, Xing WQ, Liu W, Weinstein IB: Increased expression of cyclin D1 in a murine mammary epithelial cell line induces p $27^{\mathrm{Kip} 1}$, inhibits growth, and enhances apoptosis. Cell Growth Differ 1996;7:699-710.

-31 Coleman ML, Marshall CJ, Olson MF: Ras promotes $\mathrm{p} 21^{\mathrm{WAF} 1 / \mathrm{CIP} 1}$ protein stability via a cyclin D1-imposed block in proteasome-mediated degradation. EMBO J 2003;22:20362046.

>32 Lipponen P, Aaltomaa S, Eskelinen M, Ala-Opas M, Kosma VM: Expression of p $21^{\mathrm{WAF} 1 / \mathrm{CIP} 1}$ protein in transitional cell bladder tumours and its prognostic value. Eur Urol 1998;34:237-243.

33 Peschos D, Tsanou E, Stefanou D, Damala C, Vougiouklakis T, Mitselou A, Agnantis NJ: Expression of cyclin-dependent kinases inhibitors $\mathrm{p} 21^{\mathrm{WAF} 1 / \mathrm{CIP} 1}$ and $\mathrm{p} 27^{\mathrm{Kip} 1}$ in benign, premalignant and malignant laryngeal lesions. Correlation with cell cycle regulatory proteins. In Vivo 2004; 18:719-724.

34 Zheng JY, Wang WZ, Li KZ, Guan WX, Yan $\mathrm{W}$ : Effect of $\mathrm{p} 27^{\mathrm{Kip} 1}$ on cell cycle and apoptosis in gastric cancer cells. World J Gastroenterol 2005; 11:7072-7077.

35 Eymin B, Sordet O, Droin N, Munsch B, Haugg M, Van de Craen M, Vandenabeele P, Solary E: Caspase-induced proteolysis of the cyclin dependent kinase inhibitor p27 $7^{\mathrm{Kip} 1}$ mediates its anti-apoptotic activity. Oncogene 1999;18:4839-4847.

$>36$ Masuda A, Osada H, Yatabe Y, Kozaki K, Tatematsu Y, Takahashi T, Hida T, Takahashi T, Takahashi T: Protective function of p2 $7^{\text {Kip } 1}$ against apoptosis in small cell lung cancer cells in unfavorable microenvironments. Am J Pathol 2001;158:87-96. 